\title{
RELATIONSHIP BETWEEN OBSESSIVE- COMPULSIVE DISORDERS AND DISEASES AFFECTING PRIMARILY THE BASAL GANGLIA
}

\author{
Alex S. S. Freire Maia, Egberto Reis Barbosa, Paulo Rossi Menezes and Eurípedes \\ C. Miguel Filho
}

RHCFAP/2994

MAIA, ASS et al. - Relationship between obsessive-compulsive disorders and diseases affecting primarily the basal ganglia. Rev. Hosp. Clín. Fac. Med. S. Paulo 54 (6):213-221, 1999.

SUMMARY: Obsessive-compulsive disorder (OCD) has been reported in association with some neurological diseases that affect the basal ganglia such as Tourette's syndrome, Sydenham's chorea, Parkinson's disease, and Huntington's disease. Furthermore, studies such as neuroimaging, suggest a role of the basal ganglia in the pathophysiology of OCD. The aim of this paper is to describe the association of OCD and several neurologic disorders affecting the basal ganglia, report the existing evidences of the role of the basal ganglia in the pathophysiology of OCD, and analyze the mechanisms probably involved in this pathophysiology.

DESCRIPTORS: Obsessive-compulsive disorder. Neuropsychiatry. Basal ganglia. Parkinson's disease. Tourette's syndrome. Sydenham's chorea. Huntington's disease.

Although neurology and psychiatry are generally defined as separate medical specialties, disorders affecting the brain are not always restricted in clinical expression to only one of these specialties. This is particularly true for disorders affecting the basal ganglia, in which the clinical picture is hardly ever limited to symptoms classically described as neurological or psychiatric. For this reason, a current trend is to describe these disturbances as neuropsychiatric.

Obsessive-compulsive disorder (OCD) is one example of such a neuropsychiatric disorder that has been the object of growing interest in recent years. It affects about $3 \%$ of the general population ${ }^{1}$ and is the fourth most frequent psychiatric diagnosis, surpassed only by phobias, depressions, and drug addiction. ${ }^{1}$ OCD is characterized by obsessions and/or compulsions that are intense enough to interfere in the individual's normal activities and in his social relations. Obsessions are characterized by thoughts, ideas, or images (for example repetitive doubts or thoughts about contamination) that invade the individual's awareness and are distressing and persistent. Although meaningless in themselves, the individual recognizes the obsessions as the product of his own mind and tries, albeit unsuccessfully, to extinguish them. Compulsions are intentional repetitive behaviors (for example, hand-washing and rituals like checking doors and windows, and so on) that are often carried out in response to an obsession in order to reduce or alleviate unpleasant feelings ${ }^{2}$.

OCD has recently been described in association with basal-ganglia-related neurological diseases such as Sydenham's chorea ${ }^{3,4,5,6}$, Parkinson's disease $^{7}$, and Huntington's disease ${ }^{8}$. In

From the Departments of Psychiatrics and Neurology, University of São Paulo School of Medicine, São Paulo - Brazil. addition, Tourette's syndrome also appears to be related to the basal ganglia, and is often found in association with OCD $^{9,10,11}$.

The aim of this overview is to describe the current evidence of association of OCD with several neurological diseases primarily affecting the basal ganglia, and to analyze the implications of these structures in the pathophysiology of OCD.

\section{$O C D$ and Tourette's syndrome}

Tourette's syndrome (TS) is a chronic neuropsychiatric disorder characterized primarily by the presence of motor and vocal tics, defined as sudden, rapid, repetitive, stereotyped, involuntary movements or vocalizations that can be voluntarily suppressed, even if only for a short period of time. The tics often occur in bouts and tend to become worse in moments of fatigue and tension ${ }^{12}$. 
There is much evidence in favor of an association between OCD and TS. Gilles de la Tourette himself reported obsessive-compulsive behaviors in the cases he described in 1885. Several authors have described a frequency of obsessive-compulsive behavior in patients with TS greater than that found in the general population ${ }^{9,10,11}$.

The association between OCD and TS is also borne out in genetic studies. Price et al. ${ }^{13}$, in a study of 43 pairs of twins in which one member of each pair presented TS, found obsessivecompulsive symptoms in $83 \%$ of a total 86 individuals. These authors also observed a greater frequency of obsessive-compulsive behavior among monozygotic twins (52\%) compared with dizygotic twins (15\%).

Pauls \& Leckman ${ }^{14}$ found a greater frequency of OCD in first-degree relatives of TS patients, even in the absence of tics or TS, suggesting that certain forms of OCD could represent a variant of the same genes related to TS. Pauls et al. ${ }^{14}$, in a segregation analysis study of 30 families, observed that the spectrum of TS is inherited in accordance with a dominant autosomal pattern with sex-dependent variable penetration.

Studies of patients with primary OCD have also showed a high percentage of tics, ranging from $7 \%$ to $37 \%$ $15,16,17,11$. Rosário-Campos et al. ${ }^{18}$ assessed 42 patients with OCD of whom 12 met criteria for a diagnosis of tics and/or TS. Interestingly, tics and TS occurred most frequently in the sub-group presenting earlier onset of obsessivecompulsive symptoms (before 10 years of age) when compared with later-onset patients (after 18 years of age). Additionally, tic-like compulsions were more frequent in the early-onset group than in the late-onset group (even in patients without a history of tics or TS). These results suggest that early-onset OCD is more related to the presence of tics and TS than late-onset OCD.
Miguel et al. ${ }^{11,17}$ compared the characteristics of the repetitive behavior in patients with OCD +TS in relation to a group of patients with OCD and without tics or TS. It was observed that in the patients with OCD + TS, the repetitive behaviors were less frequently preceded by cognitions (obsessions) and autonomic anxiety (e.g. dry mouth, tachycardia, sweating, pallor, breathlessness) than in patients with OCD without TS. Patients with OCD + TS also presented a greater frequency of sensory phenomena (e.g. sensations or feelings of discomfort) preceding their behaviors. Thus, patients with OCD linked to TS also differ from those without tics from a clinical point of view, and it is believed that these variables may be important as predictive factors for treatment. Finally, it should be stressed that McDougle et al. ${ }^{19}$ have recently shown that patients with OCD + tics do not respond satisfactorily to classic treatment with selective serotonin reuptake inhibitors, and that these patients can benefit from the association of these antidepressants with neuroleptics. Summing up, there is a fair amount of evidence in the literature suggesting a relationship between OCD and TS. Genetic family studies suggest that some forms of OCD may be the expression of the same genes related to TS. Phenomenological studies show that patients with OCD + TS exhibit clinical features different from those patients with OCD without tics or TS. Early-onset OCD patients appear to have several characteristics in common with patients with OCD + TS. Finally, patients with OCD + TS also appear to respond differently to common OCD treatments.

\section{OCD and Sydenham's chorea}

Sydenham's chorea (SC) is a disorder affecting the basal ganglia, characterized by choreiform movements, some degree of hypotonia and occasionally by emotional instability. SC is considered to be a complication of rheumatic fever, and therefore arthritis and carditis are other commonly associated manifestations ${ }^{20}$.

The association between OCD and SC was first established by Chapman ${ }^{3}$ in a study of 8 children with the disease, 4 of whom presented marked obsessive-compulsive symptoms (OCS), including washing rituals.

Grimshaw ${ }^{4}$, on the other hand, comparing the prevalence of neurological alterations in patients with and without obsessive characteristics, found 6 with a history of SC out of 103 obsessive patients, whereas only 2 of the 105 controls presented positive history for this condition.

In two studies, Swedo et al. ${ }^{5,6} \mathrm{de}$ scribed interesting links between OCS and SC. In the first ${ }^{5}$, children and adolescents with previous history of SC presented a greater prevalence of obsessive-compulsive symptoms when compared with a control group that had had rheumatic fever (RF) without SC. In the second study ${ }^{6}, 11$ children in the acute phase of SC were assessed in order to detect obsessive-compulsive symptomatology. Nine of them presented this type of psychiatric disorder with acute onset; none of them had previous history for OCS. Among these 9 children, 4 met criteria for OCD, 2 presented subclinical OCD, and 3 presented only OCS. The OCS began shortly before the appearance of the movement disorder, peaked during the period of most intense choreiform movements, and generally disappeared before the movements did so.

Since the OCS in these children with SC were identical to those in the children with only OCD, Swedo et al. ${ }^{6}$ put forward the hypothesis that certain cases of acute OCD in childhood might represent an autoimmune cerebral disorder with similar mechanisms to SC, even in the absence of RF. In other 
words, in genetically susceptible children, infection by group A b hemolytic streptococcus might induce the formation of antineuronal antibodies that in certain subcortical structures might lead to dysfunction of the basal ganglia. This dysfunction, in turn, might manifest itself as SC, OCD, or both.

Mercadante et al. ${ }^{21}$ recently concluded a study analyzing the prevalence of psychiatric disorders in 22 patients with RF and SC, 20 with RF but without SC, and 20 controls. A greater (but not statistically significant) frequency of OCD was found in this study in the two groups with RF when compared with the control group. The frequency of OCS in patients with only RF was significantly greater when compared with the control group; differences between the groups with and without SC with regard to OCD and OCS were not observed. In the same study, an increased frequency of tics and attention deficit disorder with hyperactivity (ADDH) was found in patients with SC. Based on these results, Mercadante et al. ${ }^{21}$ suggest a psychopathological vulnerability in patients with RF that manifests itself through a symptomatological continuum including OCS, ADDH, and movement disorders such as tics and chorea.

In conclusion, there is evidence today that OCD is not only more frequent in patients with $\mathrm{SC}$, but also in patients with RF without SC, suggesting that autoimmune mechanisms secondary to streptococcal infection could play an important role in the etiology of certain subtypes of OCD.

\section{OCD and Parkinson's disease}

Parkinson's disease (PD) is a highly-prevalent neurological disorder. Its major clinical features are akinesia, plastic hypertonia, resting tremor, and postural instability. Autonomic alterations and psychiatric disorders such as dementia and depression may also be present. Prevalence ranges from 150 to 200 cases per 100,000 individuals in the general population, increasing with age so that the prevalence of PD in individuals over 65 is $1 \%{ }^{22}$.

The main pathophysiologic aspect of PD is a decrease in dopaminergic levels owing to degeneration of melanincontaining neurons in the substantia nigra (pars compacta), which are responsible for production of this neurotransmitter. These neurons project into the striatum (caudate and putamen).

In the early twentieth century the presence of OCD in cases of post-encephalitic parkinsonism was observed $^{23}$. Lauterbach ${ }^{24}$, studying 28 families with family Parkinsonism, found a rate of OCD 5 times greater than that of the normal population.

Tomer et al. ${ }^{7}$ recently carried out a systematic study in 30 patients with PD, showing that 17 of them presented a total score for obsessive-compulsive symptoms above that of the controls. An association between motor asymmetry and the presence of obsessivecompulsive symptoms was observed in this study. The intensity of the left-side motor symptoms was associated with cleanliness worries, repetitions, and disturbing thoughts, whereas the severity of right-sided symptoms was significantly related only to obsessions with order and routine. Despite the fact that some neuroimaging studies have shown differences between the two hemispheres ${ }^{25,26,27,28}$, evidence regarding lateralized pathophysiology in OCD is inconclusive as yet.

In a preliminary analysis of a prevalence study for OCS in patients with Parkinson's disease, Maia et al. ${ }^{29}$ found OCS in 12 (24\%) of 50 patients evaluated. This study also found a preponderance of left-side motor symptoms among patients with OCS, which supports a hypothesis of a possible lateralization in the pathophysiology of $\mathrm{OCD}^{30}$.
One should remember in analyzing these results that Hardie et al. ${ }^{31}$ reported that some patients after treatment with levodopa began to present stereotyped movements, even organized rituals, suggesting that some patients with OCS and Parkinson's disease may suffer their symptoms secondary to the effect of the treatment given.

\section{$O C D$ and Huntington's Disease}

Huntington's disease (HD) is a dominant autosomal neurodegenerative disease that primarily manifests itself through choreiform movements and progressive dementia. Although there are few reports in the literature of OCD in patients with HD, Cummings \& Cunningham ${ }^{8}$ reported two cases of HD with OCD appearing after the onset of the neurological symptoms of HD. Fear of contamination and washing compulsion were present at first, followed by a compulsion to smoke and drink, without the characteristics of dependency. According to the authors, this scarcity of accounts may reflect either an actual low prevalence of OCS in patients with HD, or a failure to identify its manifestations, or even a tendency for the manifestations to appear late in the course of the disease, when patients are presenting acute cognitive disorders, making it difficult to recognize the manifestations ${ }^{8}$.

\section{OCD in other basal ganglia disorders}

Obsessive-compulsive symptoms have also been described in patients with neuroacanthocytosis ${ }^{32}$ and idiopathic spasmodic torticollis ${ }^{33}$.

Data from the literature also suggest a relation between focal cerebral lesions affecting the basal ganglia and the appearance of obsessive-compulsive symptoms. Pulst et al. ${ }^{34}$ have described OCS and tics in a patient with 
bilateral caudate lesions after carbon monoxide poisoning. Weilburg et al..$^{35}$ observed a patient with a history of neonatal hypoxia and atrophy of the left caudate and putamen who developed severe OCD in adolescence. There are also accounts of OCD occurring after bilateral caudate infarction $36,37,38$ and OCS after globus pallidus lesions caused by carbon monoxide poisoning ${ }^{39,40}$ and post-anoxia ${ }^{39}$.

The basal ganglia and the pathophysiology of $O C D$

The basal ganglia are deep subcortical structures represented by the striatum (caudate and putamen), globus pallidus, substantia nigra, and the subthalamic nucleus of Luys.

The anatomic connections of the basal ganglia provide some evidence of the participation of these structures in non-motor functions. Of particular importance are the connections between the basal ganglia and the limbic system. Many limbic projections into the striatum are already known, mainly deriving from the hippocampus, cingulate cortex, and amygdala. In addition to the primary motor region, however, other cortical regions - above all the frontal cortex - send projections to the basal ganglia.

In 1983, De Long et al. ${ }^{41}$ proposed the existence of two loops involving the basal ganglia. The motor loop, centered in the putamen, received afferent projections from the sensory-motor cortex and sent projections to the premotor areas of the frontal cortex via the globus pallidus and thalamus. The complex loop, involving afferent projections from the associative areas of the frontal cortex, projected into the caudate nucleus and striatal-pallidalthalamic-cortical pathways towards the prefrontal cortex.

According to studies by Alexander et al. ${ }^{42}$, it is currently thought that five parallel circuits exist that are responsible for frontal-striatal connections: the motor circuit, the oculomotor circuit, the dorsolateral prefrontal circuit, the lateral orbitofrontal circuit, and the anterior cingulate. Figure 1 shows these circuits, except for the oculomotor circuit, which is a variant of the motor circuit.

Analyzing these frontal-striatal circuits, one can observe that cortical areas project with somatotypical organization into the striatum (putamen, caudate, and nucleus accumbens). These projections are mediated by the excitatory neurotransmitter glutamate. The connections between the striatum and the inner globus pallidus-substantia nigra (pars reticulata) complex take two pathways (Figure 2): the direct (inhibitory) pathway and the indirect pathway, which goes through the external globus pallidus and the subthalamic nucleus of Luys (excitatory). Efferent GABA-ergic projections leave the globus pallidus-substantia nigra complex for the thalamus. Finally, thalamic nuclei (lateral ventral, anterior ventral, and medial dorsal), establish feedback loops by projecting into specific regions of the frontal lobe. These thalamo-cortical projections are believed to be excitatory and use aspartate or glutamate as the neurotransmitter.

The putamen, mainly associated with motor aspects, and the caudate and nucleus accumbens, related to $\operatorname{cog}$ nitive and behavioral aspects, can be distinguished within the striatum. However, given the overlap of different cortical projections into the striatum, this division should be considered a continuous transition without defined limits ${ }^{43}$.

Other hypotheses relating to the organization of the striatum exist. Graybiel et al. ${ }^{44,45}$ propose that the striatum can be divided into two distinct compartments: the matrix, which is mainly related to sensory-motor processing, and the striosome, which receives afferent projections from structures associated with the limbic system and associative areas. Both components of the striatum, putamen and cau-

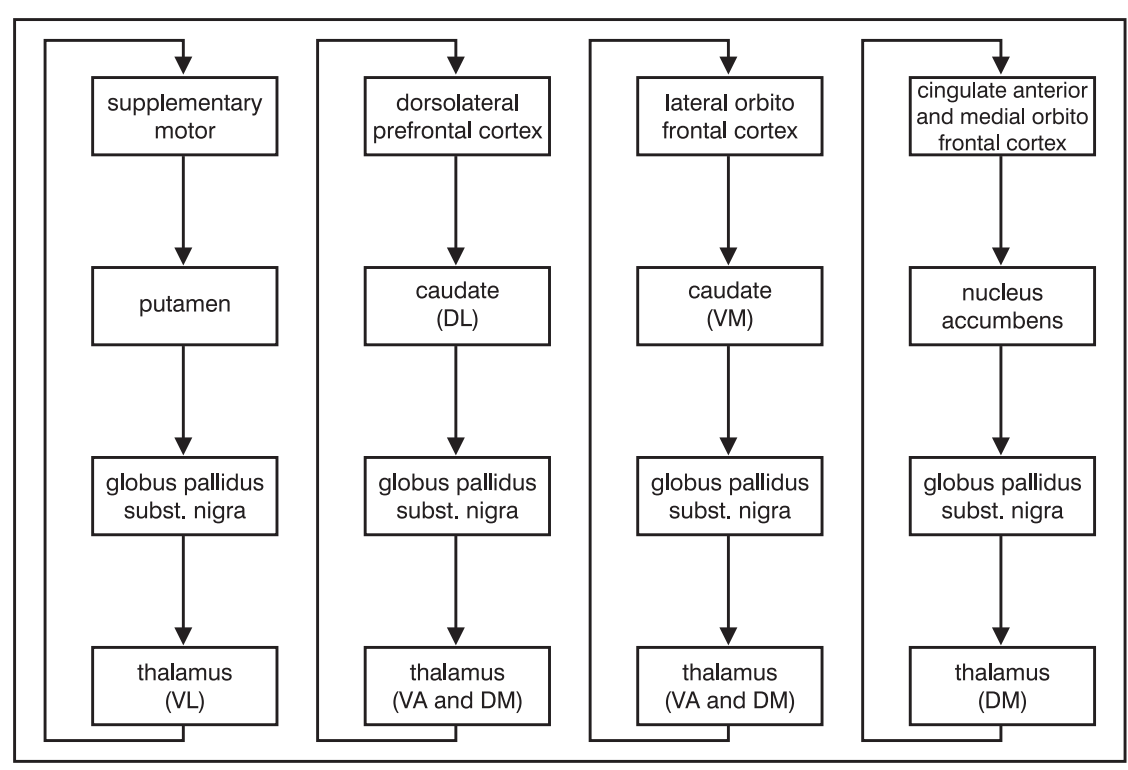

Figure 1 - Frontal-striatal connections.

DL: dorsolateral; DM: dorsomedial; VL: ventrolateral;

VA: ventroanterior; VM: ventromedial. 


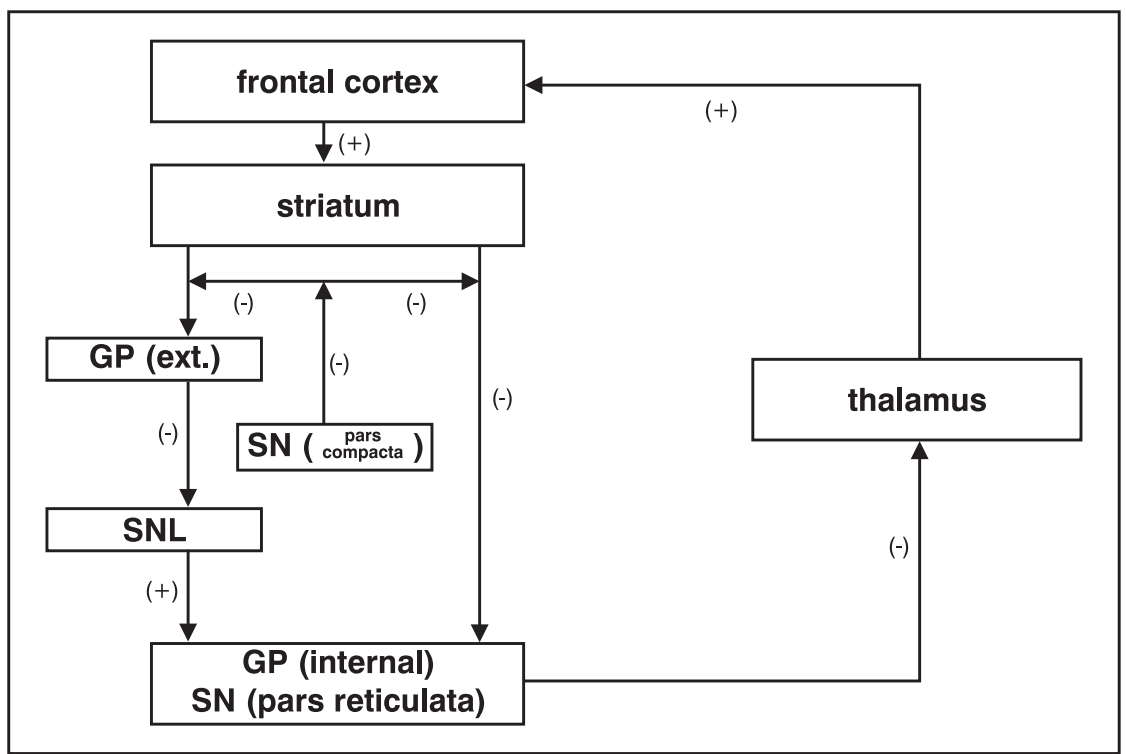

Figure 2 - Corticostriate projections.

GP: globus pallidus; SN: substantia nigra; SNL: subthalamic nucleus of Luys.

date, contain matrix and striosomes. This concept stemmed from studies showing the presence of small acetylcholinesterase-poor regions (striosomes) between acetylcholinesteraserich areas (matrix). These regions were later found to differ with regard to several other neurotransmitters ${ }^{45}$. The striosome/matrix division is therefore based on neurochemical data, while the individuality of the caudate and putamen has an anatomic basis.

In addition to anatomic connections, neuroimaging studies have suggested the participation of the basal ganglia in the pathophysiology of OCD. Several studies using both cranial tomography and magnetic resonance imaging have shown the loss of the asymmetry normally observed in caudate nuclei, the left being larger than the right, in patients with OCD or TS ${ }^{25,26,27,28}$. On the other hand, other authors have shown a reduction in size of the lenticular nucleus (globus pallidus and putamen) in magnetic resonance imaging of patients with TS, however without a change in the caudate volume $\mathrm{e}^{46,47}$. The use of functional neuroimaging enabled Baxter et al..$^{48,49}$ to identify, through positron emission tomography (PET-scan), an increase in glucose metabolism in the caudate nucleus and the orbitofrontal region of patients with OCD, when compared to controls. Later PET-scan studies ${ }^{50}$ and single-photon emission computed tomography (SPECT) studies ${ }^{51}$ also showed an increase of metabolic activity in the orbitofrontal region ${ }^{51}$, and Swedo et al. ${ }^{52}$ observed a correlation between this increased activity and the intensity of obsessive-compulsive symptoms.

Functional neuroimaging studies of patients with OCD before and after treatment have shown interesting results. Baxter et al. ${ }^{48,53}$ observed a relation between decreased metabolic activity of the caudate nucleus and improvement of symptoms after treatment, and showed later that this decrease in metabolic activity of the head of the caudate nucleus occurred not only after pharmacologic treatment, but also after behavioral psychotherapeutic treatment. Benkelfat et al. ${ }^{54}$ found a decrease of metabolism of the left caudate after treatment with clomipramine. Swedo et al. ${ }^{55}$, also assessing patients pre- and post-treatment, showed a correlation between an increase in activity in the right orbitofrontal region and improvement in symptoms after drug therapy. Based on such data, Baxter et al. ${ }^{53}$ proposed a hypothesis that there is an initial alteration in the caudate and a later one in the orbitofrontal region.

Interesting PET-scan analyses of cerebral activity have been carried out during provocation of obsessive-compulsive symptoms. This provocation was undertaken, for instance, in the case of a patient with obsessions of contamination, by wearing gloves previously contaminated by himself, in comparison with a control state in which the same patient wore sterile gloves. Patterns of cerebral metabolic activity consistent with other patterns already alluded to - hyperactivity of the caudate, thalamus and orbitofrontal cortex - were found in these studies 56,57 . Rauch et al. ${ }^{56}$ have also observed greater activity of the left anterior cingulate cortex.

In addition to neuroimaging data, the classic neuropsychological methods also bear out the hypothesis of the participation of the basal ganglia in the pathophysiology of OCD. One should remember that neuropsychological alterations can sometimes be detected even in the absence of a detectable structural pathology ${ }^{58}$.

Neuropsychological studies with obsessive-compulsive patients have shown similar results to those in patients with Parkinson's or Huntington's disease. Studies of OCD have shown impairment of visuospatial ability 59,60,61,62, non-verbal memory ${ }^{61,63,64}$, and executive functions $59,65,66,67,64$.

Memory impairment seems to be mainly linked to the implicit mechanism of the memory. Storage and recall of this type of memory is not totally dependent on awareness or cog- 
nitive processes. It consists of a relatively slow process that takes place through repetition of tasks, and is characterized by a performance improvement in the execution of such tasks ${ }^{68}$.

Alterations in implicit memory may reflect a dysfunction of the striatum, probably involved with this modality of memory. Rauch et al. ${ }^{58}$ proposed that the striatum carries out simpler functions, facilitating good performance of frontal cortex functions (which are responsible for more complex operations), in order to relieve it of some portion of computational work related primarily to processing unconscious information. Some authors suggest that impairment of executive functions alters the planning, organization, and ability to alter "patterns", leading to visuospatial and memory deficits. ${ }^{58}$.

On the basis of anatomic knowledge and data obtained mainly through neuroimaging studies, Baxter et al. ${ }^{53}$ have advanced a model that is interesting with regard to the participation of the basal ganglia in the pathophysiology of OCD. According to their model, the cortical-striatal-thalamic-cortical circuits act as filters in order to inhibit irrelevant thoughts.

According to this concept, a dysfunction of the caudate nucleus would lead orbital cortex impulses not to be suitably "filtered" (repressed), activating the direct pathway. Thus, the inhibitory impulses of the caudate over the globus pallidus would increase. This inhibition would result in less inhibition of the thalamus by the globus pallidus, and consequently, excitatory thalamic impulses to the orbital cortical regions would make a reinforcement loop. These changes would lead to a failure to inhibit irrelevant worries, which thus receive disproportional at- tention (obsessions) and trigger repetitive, senseless behaviors (compulsions).

\section{Implications for the treatment of $O C D$}

The knowledge acquired through these studies stimulated proposals for other OCD treatments. In addition to the already existing pharmacologic approaches, such as the use of serotonin reuptake inhibitors (SRIs), there are surgical approaches, and most recently, the emergence of repetitive transcranial magnetic stimulation - rTMS.

With regard to surgical approaches, recent studies suggest that several procedures (e.g. anterior cingulotomy, anterior capsulotomy, tractotomy of the subcaudate, and limbic leukotomy) may be effective in OCD cases refractory to usual treatment. Baer et al. ${ }^{69,70}$ have confirmed relative security and effectiveness (around 30\% of patients presented marked improvements) in the case of cingulotomy (stereotaxic transection of the tracts from the frontal cortex to subcortical sites - caudate) as a treatment for patients with severe OCD that is refractory to other forms of treatment. Capsulotomy (lesion of the internal capsule containing fibers interconnecting the orbitofrontal region and the dorso-medial nucleus of the thalamus and other related areas) has been performed in Europe for three decades for refractory anxiety disorders. A promising new technique is the "gamma knife", which makes a small lesion in the anterior portion of the internal capsule ${ }^{71}$. This procedure has proved effective in a significant percentage of patients (around 60\%), and has advantages including the fact that craniotomy is not necessary and that the patient does not need a lengthy hospital stay after the operation ${ }^{71}$.

rTMS is a new non-invasive technique involving direct stimulation of cortical neurons, which can cause alterations in cerebral activity, and can be used for therapeutic purposes ${ }^{72}$. It is believed that specific cerebral circuits, such as those involved in OCD, can be inhibited or stimulated by these techniques. Greenberg et al. ${ }^{73}$ observed that a single session of rTMS, aimed at the right orbitofrontal cortex, produced a reduction in compulsions for a roughly 8 -hour period. The mechanisms by which this technique benefited these patients, however, need deeper study.

In conclusion, therefore, there is evidence in favor of participation of the basal ganglia in the pathophysiology of OCD. These data have diagnostic and therapeutic implications for the clinical practice both of neurologists and psychiatrists. In other words, in patients with OCD, the psychiatrist should be aware that the presence of other disorders involving the basal ganglia, such as Tourette's syndrome, Sydenham's chorea, Huntington's disease, and Parkinson's disease may be related to this disorder. Similarly, neurologists should investigate obsessivecompulsive symptoms when treating patients with these diseases. Finally, it is believed that a greater understanding of the role of the basal ganglia in OCD may be useful in developing new therapeutic approaches.

ACKNOWLEDGEMENTS: This study is being supported by a grant from FAPESP * (The São Paulo State Foundation for Research Support) - (processes: 95/5012-7, 96/ 7425-0, 96/11991-0, 97/5815-8). 
MAIA, ASS e col. - Relação entre transtorno obsessivo-compulsivo e doenças neurológicas dos gânglios da base. Rev. Hosp. Clín. Fac. Med. S. Paulo 54 (6):213-221, 1999.

O transtorno obsessivo-compulsivo (TOC) tem sido reportado em associação com algumas doenças neurológicas que afetam primariamente os gânglios da base como a síndrome de Tourette , a coréia de Sydenham, a doença de Parkinson e a doença de Huntington. Da mesma forma, estudos de neuroimagem sugerem a participação dos gânglios da base na fisiopatologia do TOC. O objetivo deste estudo é rever a coexistência de TOC e várias doenças que afetam os gânglios da base, as evidências da participação dessas estru- turas na fisiopatologia do TOC e os mecanismos neurais subjacentes a esse distúrbio psiquiátrico.

DESCRITORES: Transtorno o b s e s sivo - c o m p u l sivo . Neuropsiquiatria. Gânglios da base. Doença de Parkinson. Síndrome de Tourette. Coréia de Sydenham. Doença de Huntington.

\section{REFERENCES}

1. KARNO M \& GOLDING JM - Obsessive Compulsive Disorder. In: ROBINS LN \& REGIER DA eds - Psyschiatric Disorders in America. The Epidemiologic Catchment Area Study. New York, Free Press, 1991.

2. MIGUEL EC - Transtornos do espectro obsessivo-compulsivo: diagnóstico e tratamento. Rio de Janeiro, Guanabara Koogan, 1996.

3. CHAPMAN AH, PILKEY L \& GIBBONS MJ - A psychosomatic study of eight children with Sydenham's chorea. Pediatrics 1958; 21: 582-595.

4. GRINMSHAW L - Obsessional disorder and neurological illness. J Neurol Neurosurg Psychiatry 1964; 27: 229-231.

5. SWEDO SE, RAPOPORT JL, CHESLOW DL et al. - High prevalence of obsessive-compulsive symptoms in patients with Sydenham's chorea. Am J Psychiatry 1989; 146: 246-249.

6. SWEDO SE, LEONARD HL, SCHAPIRO MB et al. - Sydenham's chorea: physical and psychological symptoms of St. Vitus dance. Pediatrics 1993; 91: 706-713.

7. TOMER R, LEVIN BE \& WEINER WJ - Obsessive-compulsive symptoms and motor asymmetries in Parkinson's disease. Neuropsych Neuropsychol Behav Neurol 1993; 6:26-30.

8. CUMMINGS JL \& CUNNINGHAM K - Obsessive-compulsive disorder in Huntington disease. Biol Psychiatry 1992; 31: 263-270.

9. CAINE ED, MCBRIDE MC, CHIVERTON P et al. - Tourette's syndrome in Monroe County school children. Neurology 1988; 38: $472-475$.

10. SINGER HS \& ROSENBERG LA - The development of behavioral and emotional problems in Tourette's syndrome. Pediatr Neurol 1989; 5: 41-44.

11. MIGUEL EC, BAER L, COFFEY, BJ et al. - Phenomenological differences appearing with repetitive behaviours in obsessivecompulsive disorder an Gilles de la Tourette's syndrome. Br J Psychiatry 1997; 170: 140-145.

12. BRITO GNO - Síndrome de Tourette: Clínica, terapêutica e modelo neurobiológico. In: MIGUEL EC - Transtornos do espectro obsessivo-compulsivo: diagnóstico e tratamento. Rio de Janeiro, Guanabara Koogan, 1996.
13. PRICE RA, KIDD KK, COHEN DJ et al. - A twin study of Tourette syndrome. Arch Gen Psychiatry 1985; 42: 815-820.

14. PAULS DL \& LECKMAN JF - The inheritance of Gilles de la Tourette's Syndrome and associated behaviors. N Engl J Med 1986; 315: 993-997.

15. RASMUNSEN AS \& EISEN JL - Epidemiology and clinical features of obsessive-compulsive disorder. In: JENIKE M, BAER L, MINICHELLO W, eds. - Obsessive-compulsive disorder: therapy and management. Chicago, Yr Bk Med Pub, 1990.

16. PITTMAN RK, GREEN RC, JENIKE MA et al. - Clinical comparison of Tourette's disorder and obsessive-compulsive disorder. Am J Psychiatry 1987; 144: 1166-1171.

17. MIGUEL EC, COFFEY BJ, BAER, L et al.- Phenomenology of intentional repetitive behaviors in obsessive-compulsive disorder and Tourette's disorder. J Clin Psychiatry 1995; 56: 246-255.

18. ROSÁRIO-CAMPOS MC - Transtorno Obsessivo-Compulsivo de início precoce e de início tardio: características clínicas, psicopatológicas e de comorbidade. São Paulo, 1998. (Tese Mestrado, Faculdade de Medicina da Universidade de São Paulo).

19. MCDOUGLE CJ, GOODMAN WK, LECKMAN JF et al. - Haloperidol addition in fluvoxamine-refractory obsessive compulsive disorder. A double-blind, placebo-controlled study in patients with and without tics. Arch Gen Psychiatry 1994; 51: 302-308.

20. ASBAHR FR - Coréia de Sydenham e transtorno obsessivocompulsivo. In: MIGUEL, EC - Transtornos do espectro obsessivo-compulsivo: diagnóstico e tratamento. Rio de Janeiro, Guanabara Koogan, 1996. p.158-162.

21. MERCADANTE MT et al. - Rheumatic fever and co-morbid psychiatric disorders. Am J. Psychiatry (in print).

22. RAJPUT AH, OFFORD AP, BEAR CM et al. - Epidemiology of Parkinson's disease: incidence, classification and mortality. Ann Neurol 1984, 16: 78-132.

23. JELLIFE SE - Psychopathology of forced movements and the oculogyric crises of lethargic encephalitis. Nervous \& Mental Diseases Monograph. New York \& Washington, 1932. (Monograph n55). 
24. LAUTERBACH EC \& DUVOISIN RC - Neuropsychiatric correlates of familial parkinsonism. Neurology 1987; 37 (1).

25. LUXEMBERG J, SWEDO SE, FLAMENT MF et al. - Neuroanatomic abnormalities in obsessive-compulsive disorder detected with quantitative X-ray computed tomography. Am J psychiatry 1988; 145: 1089-1094.

26. ROBINSON D, WU H, MUNNE RA et al. - Reduced caudate nucleus volume in obsessive-compulsive disorder. Arch Gen Psychiatry 1995; 52: 393-398.

27. SCARONE S, COLOMBO C, LIVIAN S et al. - Increased right caudate nucleus size in obsessive-compulsive disorder: detection with magnetic resonance imaging. Psychiatry Res Neuroimaging 1992; 45: 115-121.

28. JENIKE MA, BREITER HC, BAER L et al. - Cerebral structural abnormalities in obsessive-compulsive disorder: a quantitative morphometric magnetic resonance imaging study. Arch Gen Psychiatry 1996; 53:625-32.

29. MAIA AS, PINTO ASS, BARBOSA ER et al. - Obsessive-compulsive symptoms in patients with Parkinson's disease. In: AMERICAM PSYCHIATRIC ASSOCIATION ANNUAL MEETING, $15^{\text {th }}$, Toronto, Canadá, 1998. (New Research- Program \& Abstracts, NR 137, p.105)

30. PINTO AS, MAIA A, BARBOSA E et al. - Parkinson 's disease and obsessive-compulsive symptoms. In: CONGRESSO BRASILEIRO DE NEUROLOGIA, 18 ${ }^{\text {th }}$, São Paulo, 1998. Arch Neuro-Psiquiatr, Supl 1(5): 209).

31. HARDIE RJ, LEES AJ \& STERN GM - On-off fluctuations in Parkinson's disease. Brain 1984; 107: 487-506.

32. MIRANDA M, CAMPERO M, TENHAMM, E et al. - Neuroacantocitosis: comunicacion de 3 casos. Rev Med Chile 1993; 21: 176-179.

33. BIHARI K, HILL JL \& MURPHY DL - Obsessive-compulsive characteristics in patients with idiopathic spasmodic torticollis. Psychiatry Res 1992; 42: 267-272.

34. PULST SM, WALSHE TM \& ROMERO JA - Carbon monoxide poisoning with features of Gilles de la Tourette's syndrome. Arch Neurol 1983; 40: 443-444.

35. WEILBURG JB, MESULAM MM, WEINTRAUB $S$ et al. - Focal striatal abnormalities in a patient with obsessive-compulsive disorder. Arch Neurol 1989; 46: 233-235.

36. CROISILE B, TOURNIAIRE D, CONFRAVEUX C et al. - Bilateral damage to the head of the caudate nuclei. Ann Neurol 1989; 25: 313-314.

37. TRILLET M, CROISILE B, TOURNIAIRE D et al. - Perturbations de l'activité motrice volontaire et lésions de noyaux caudés. Rev Neurol 1990; 146: 338-344.

38. WILLIAMS AC, OWEN C \& HEATH DA - A compulsive movement disorder with cavitation of caudate nucleus. J Neurol Neurosurg Psychiatry 1988; 51: 447-448.

39. LAPLANE D, LEVASSEUR M, PILLON B et al. - Obsessivecompulsive and other behavioural changes with bilateral basal ganglia lesions. Brain 1989; 112: 699-725.

40. ALI-CHERIF A, ROYERE ML, GOSSET A et al. - Troubles du comportement et de l'activité mentale après intoxication oxycarbonée. Rev Neurol (Paris), 1984; 140: 401-405.

41. DE LONG MR, GEORGOPOULOS AP \& CRUTCHER, MD - Corticobasal ganglia relations and coding of motor performance. Exp Brain Res 1983; 7: 30-40.

42. ALEXANDER GE, CRUTCHER MD \& DE LONG MR - Basal ganglia-thalamocortical circuits: parallel substrates for motor, oculomotor, "prefrontal" and "limbic" functions. Prog Brain Res 1990; 85: 119-146.

43. MELLO LEAM \& VILLARES J - Neuroanatomy of the basal ganglia. In: MELLO L et al. - Neuropsychiatry of the basal ganglia. Psychiatric Clinics of North America. Philadelphia, Saunders, 1997.

44. GRAYBIEL AM \& RAGSDALE CW - Histochemically distinct compartments in the striatum of human, monkey, and cat demonstrated by acetylcholinesterase staining. Proc Natl Acad Sci SA $1978, \mathbf{7 5 : 5 7 2 3 - 5 7 2 6 .}$
45. GRAYBIEL AM, RAGSDALE CW, YONEOKA ES et al. - An immunohistochemical study of enkephalin and other neuropeptides in the striatum of the cat with evidence that opiate peptides are arranged to form mosaic patterns in register with striosomal compartments visible by acetylcholinesterase staining. Neuroscience 1981; 6:377-397.

46. PETERSON B, RIDDLE MA, COHEN DJ et al. - Reduced basal ganglia volumes in Tourette's syndrome using three-dimensional reconstruction techniques from magnetic resonance images. Neurology 1993; 43: 941-949.

47. SINGER HS, REISS AL, BROWN JE et al. - Volumetric MRI changes in basal ganglia of children with Tourette's syndrome. Neurology 1993; 43: 950-956.

48. BAXTER LR, PHELPS ME, MAZZIOTA JC et al. - Local cerebral glucose metabolic rates in obsessive-compulsive disorder. A comparison with rates in unipolar depression and in normal controls. Arch Gen Psychiatry 1987; 44: 211-218.

49. BAXTER L, SCHWARTZ J, MAZZIOTA J et al. - Cerebral glucose metabolic rates in non-depressed patients with obsessivecompulsive disorder. Am J Psychiatry 1988; 145: 1560-1563.

50. NORDHAL TE, BENKELFAT C, SEMPLE W et al. - Cerebral glucose metabolic rates in obsessive-compulsive disorder. Neuropsychopharmacology 1989; 2: 23-28.

51. RUBIN RT, VILLANUEVA-MEYER J, ANANTH J et al. - Regional xenon 133 cerebral blood flow and cerebral technetium $99 \mathrm{~m}$ HMPAO uptake in unmedicated patients with obsessive-compulsive disorder and matched normal control subjects. Determination by high-resolution single photon emission computed tomography. Arch Gen Psychiatry 1992; 49: 695-702.

52. SWEDO SE, SCHAPIRO MB, GADY CL et al. - Cerebral glucose metabolism in childhood-onset obsessive-compulsive disorder. Arch Gen Psychiatry 1989; 46: 518-523.

53. BAXTER LR, SCHWARTZ JM, BERGMAN KS et al. - Caudate glucose metabolic rate changes with both drug and behaviour therapy for obsessive-compulsive disorder. Arch Gen Psychiatry 1992; 49: 681-689.

54. BENKELFAT C, NORDAHL TE, SEMPLE WE et al. - Local cerebral glucose metabolic rates in obsessive-compulsive disorder: patients treated with clomipramine. Arch Gen Psychiatry 1990; 47: 840848.

55. SWEDO S, PIETRINI P, LEONARD LH et al. - Cerebral glucose metabolism in childhood-onset obsessive-compulsive disorder. Revisualisation during pharmacotherapy. Arch Gen Psychiatry 1992; 49: 690-694.

56. RAUCH SL, JENIKE MA, ALPERT NM et al. - Regional cerebral blood flow measured during symptom provocation in obsessive-compulsive disorder using oxygen 15-labeled carbon dioxide and positron emission tomography. Arch Gen Psychiatry 1994; 51: 62-70.

57. MCGUIRE PK, BENCH CJ, FRITH CD et al. - Functional anatomy of obsessive-compulsive phenomena. Br J Psychiatry 1994; 164: 459-468.

58. RAUCH SL \& SAVAGE CR - Neuroimaging and neuropsychology of the striatum: bridging basic science and clinical practice. Neuropsychiatry of the basal ganglia. Psychiatric clinics of North America. Philadelphia, Saunders, 1997.

59. ARONOWITZ BR, HOLLANDER E, DECARIA C et al. Neuropsychology of obsessive-compulsive disorder: Preliminary findings. Neuropsych Neuropsychol Behav Neurol 1994; 7:81-86.

60. BEHAR D, RAPOPORT JL, BERG CJ et al. - Computerized tomography and ]neuropsychological test measures in adolescents with obsessive-compulsive disorder. Am J Psychiatry 1984; 141:363-368.

61. BOONE KB, ANANTH J, PHILPOTT L et al. - Neuropsychological characteristics of nondepressed adults with obsessive-compulsive disorder. Neuropsych Neuropsychol Behav Neurol 1991; 4:96-109.

62. HOLLANDER E, COHEN L, RICHARDS M et al. - A pilot study of the neuropsychology of obsessive-compulsive disorder and Parkinson's disease: basal ganglia disorders. J Neuropsychiatry $1993 ; 5: 104-106$ 
63. CHRISTENSEN KJ, KIM SW, DYSKEN MW et al. - Neuropsychological performance in obsessive-compulsive disorder. Biol Psychiatry 1992, 31:4-18.

64. ZIELINSKI CM, TAYLOR MA \& JUZWIN KR. - Neuropsychological deficits in obsessive-compulsive disorder. Neuropsych Neuropsychol Behav Neurol 1991; 4:110-126.

65. HARVEY NS - Impaired cognitive set-shifting in obsessive-compulsive neurosis. IRCS Med Sci 1986; 14:936-937.

66. HEAD D, BOLTON D, HYMAS N et al. - Deficit in cognitive shifting ability in patients with obsessive-compulsive disorders. Biol Psychiatry 1989; 25:929-937

67. MALLOY P - Frontal lobe dysfunction in obsessive-compulsive disorder. In :PERECMAN E - The Frontal Lobes Revisited. New York, IRBN Press, 1987,

68. KANDEL ER, SCHWARTZ JH \& JESSEL TM - Essentials of Neural Science and Behavior. Prent Hall Int 1995.
69. BAER L, RAUCH SL, BALLANTINE HT et al. - Cingulotomy for intractable obsessive-compulsive disorder: prospective long-term follow-up of 18 patients. Arch Gen Psychiatry 1995; 52:384-392.

70. BAER L - Factor analysis of symptom subtypes of obsessive compulsive disorder and their relation to personality and tics. J Clin Psychiatry 1993; 55:[3, suppl] 18-23.

71. MINDUS P \& JENIKE MA - Neurosurgical treatment of malignant obsessive-compulsive disorder. Psychiatric Clin North Am 1992; 15(4):921-938.

72. GEORGE MS, WASSERMANN EM \& POST RM - Transcranial Magnetic Stimulation: A neuropsychiatric tool for the $21^{\text {st }}$ century. J Neuropsych Clin Neurosci 1996; 8:373-382.

73. GREENBERG BD, MCCANN UD, BENJAMIN J et al. - Repetitive TMS as a probe in anxiety disorders: theoretical considerations and case reports. CNS Spectrums 1997; 2(1): 47-52, 1997.

Received for publication on the 21/09/99 